\title{
Recognition of anti-mycolic acid antibody at self-assembled mycolic acid antigens on a gold electrode: a potential impedimetric immunosensing platform for active tuberculosis $\dagger$
}

\author{
Nsovo S. Mathebula, ${ }^{a}$ Jeseelan Pillay, ${ }^{a}$ Gianna Toschi, ${ }^{a}$ Jan A. Verschoor ${ }^{b}$ \\ and Kenneth I. Ozoemena $* a c$
}

Received (in Cambridge, UK) 13th March 2009, Accepted 28th April 2009

First published as an Advance Article on the web 15th May 2009

DOI: $10.1039 / b 905192 a$

\begin{abstract}
Electrochemical impedimetric recognition by anti-mycolic acid antibodies, present in tuberculosis (TB)-positive human serum co-infected with human immunodeficiency virus (HIV), of mycolic acids (MA) integrated into a self-assembled monolayer of $\mathrm{N}$-(2-mercaptoethyl)octadecanamide on a gold electrode is described, proving that the MA-based electrode can satisfactorily discriminate between a TB-positive and a TB-negative serum, thus offering promise as a potential impedimetric immunosensing platform for active tuberculosis.
\end{abstract}

Tuberculosis (TB) is one of the most life-threatening infectious diseases in the world, with 3 million deaths and 8 million new cases per year. TB is the major cause of death in HIV/AIDS co-infected individuals. ${ }^{1}$ There is therefore an urgent need for new surrogate markers for the diagnosis of TB especially in sub-Saharan Africa, where the population is most burdened by the HIV/AIDS pandemic. Mycolic acids (MAs) are long-chain $\left(\mathrm{C}_{60}-\mathrm{C}_{90}\right)$, high molecular weight $\alpha$-alkyl- $\beta$-hydroxy fatty acids that constitute the major chemical components of the cell walls of Mycobacterium tuberculosis (M. tuberculosis) and related organisms. The use of free MA as antigens for the serodiagnosis of $\mathrm{TB}$ is known. ${ }^{2}$ Interestingly, irrespective of the severity of the immune deficiency measured by the fall of the CD4 T cell count, HIV-TB co-infected patients maintain high antibody levels to MA. Regrettably, however, one of the factors that conspire against the use of free MA in serodiagnostic enzyme-linked immunosorbent assay (ELISA) of TB is low accuracy $(57 \%){ }^{2}$ Moreover, ELISA requires extra enzyme-labelled antibodies and intense sample clean-up to operate, thus restricting its application for point-of-care testing. Hitherto, no single ELISA test has succeeded as a reliable test to confirm TB. Culture analysis of sputum, which is the gold standard for TB detection, usually takes 4-8 weeks for completion, leading to delayed diagnosis, patient care and TB control. HIV-infected patients and children often do not produce sputum of desired quality for TB detection.

${ }^{a}$ Department of Chemistry, University of Pretoria, South Africa

${ }^{b}$ Department of Biochemistry, University of Pretoria, South Africa

${ }^{c}$ Energy \& Processes Unit, Materials Science \& Manufacturing, Council for Scientific and Industrial Research (CSIR), Pretoria, Pretoria0001, South Africa. E-mail: kozoemena@csir.co.za;

Fax: + 27-12-8412135; Tel: + 27-12-8413664

$\dagger$ Electronic supplementary information (ESI) available: Detailed experimental information, comparative cyclic voltammograms and Nyquist plots of bare $\mathrm{Au}, \mathrm{Au}-\mathrm{MEODA}$ and Au-MEODA-MA; Nyquist plots of $\mathrm{HIV}^{-}-\mathrm{TB}^{-}$serum; degree of inhibition vs. $\mathrm{HIV}^{+}-\mathrm{TB}^{+}$serum concentrations. See DOI: 10.1039/b905192a
Electrochemical methods are useful in immunosensing, ${ }^{3}$ are relatively cheap and easy to miniaturize for point-of-care analysis, but they have rarely been reported for TB analysis, ${ }^{4,5}$ and such reports have neither used free nor immobilized MA nor real human TB serum for analysis.

Electrochemical impedance spectroscopy (EIS)-based immunosensors could offer the possibility of label-free immunosensing, ease of miniaturization, low cost of electrode mass production, and low cost instrumentation. While an impedimetric method has been reported for effective use in bioelectroanalysis such as in monitoring protein-DNA interaction, ${ }^{6}$ it has never been considered as a viable method for the sensing of antibodies for $\mathrm{TB}$ diagnosis. In this communication, we prove that MA could be strongly integrated into a self-assembled monolayer (SAM) of long-chain organothiolate, $N$-(2-mercaptoethyl)octadecanamide (MEODA), and employed for sensitive impedimetric detection of anti-MA antibodies as surrogate markers for active TB in a human serum sample from a HIV-positive patient.

Scheme 1 depicts the fabrication of electrodes as detailed in the experimental (see ESI $\dagger$ ). The Au-MEODA was formed by first creating a cysteamine monolayer as described before, followed by covalent attachment of the stearic acid (Sigma) using the well established carbodiimide coupling chemistry to form an amide bond (see ESI $\dagger$, Scheme S1).

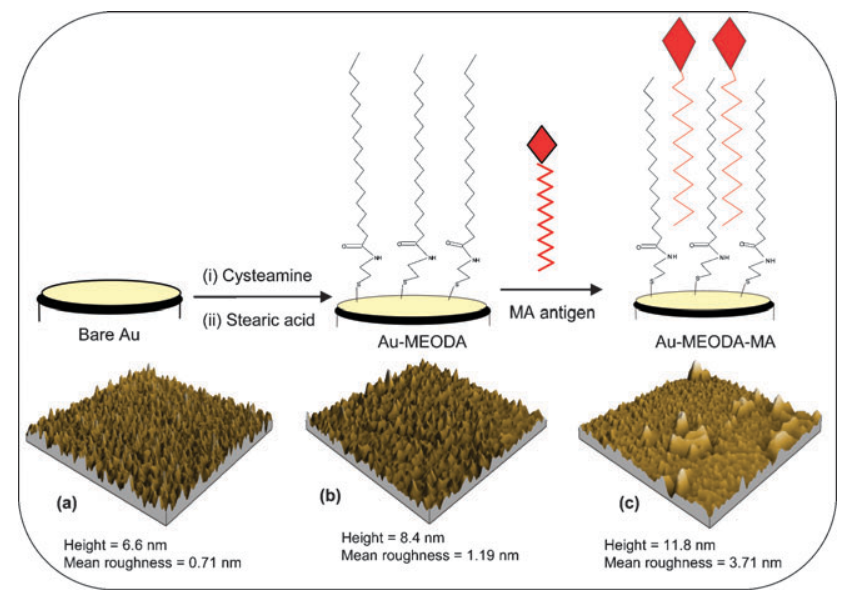

Scheme 1 Representation of self-assembly of MEODA and MA on gold surface. The fabrication conditions are as stated in the experimental section, cartoons not drawn to scale. The images are the corresponding micrographs of (a) bare gold, (b) Au-MEODA, and (c) $\mathrm{Au}-\mathrm{MEODA}-\mathrm{MA}$ obtained from the AFM experiments. 
Mycolic acids (isolated from a culture of $M$. tuberculosis H37Rv, American Type Culture Collection 27294) were integrated into the MEODA SAM (to form the $\mathrm{Au}-\mathrm{MEODA}-\mathrm{MA})$ by incubating the electrode in dry DMF solution of MA for about $48 \mathrm{~h}$ at room temperature. The success of the modification processes was first confirmed by the comparative AFM images of the (a) bare $\mathrm{Au}$, (b) Au-MEODA and (c) Au-MEODA-MA (Scheme 1). The attachment of MEODA and MA was confirmed by the increase in height from $6.6 \mathrm{~nm}$ for the bare Au to $11.8 \mathrm{~nm}$ for the Au-MEODA-MA, and roughness factor from $0.71 \mathrm{~nm}$ for the bare Au to $3.71 \mathrm{~nm}$ for the Au-MEODA-MA. The formation of the amide bond was confirmed from XPS (not shown). From the AFM topography, MEODA-MA appeared as loosely-packed aggregated bundles of species with vertical orientation. MA monolayers are known to exist in differently folded molecular conformations to give a hydrophobic surface. ${ }^{8}$ Thus, we may associate the bundle-like, aggregated state to the strong van der Waal's hydrophobic attractive forces existing between the alkyl chains of the MA and MEODA.

Cyclic voltammetry and EIS were used to establish the extent to which the modifiers (MEODA, MA and SAP) permit electron transport between a solution redox probe $\left(\left[\mathrm{Fe}(\mathrm{CN})_{6}\right]^{4-} /\left[\mathrm{Fe}(\mathrm{CN})_{6}\right]^{3-}\right)$ and the underlying gold electrode. The respective voltammograms did not show any detectable deviations even after 20 repetitive cyclic voltammetric scans, indicating electrochemical stability. The peak-to-peak separation $\left(\Delta E_{\mathrm{p}}\right.$, Fig. S1, ESI $\left.\dagger\right)$ decreased as bare $\mathrm{Au}$ $\left(\Delta E_{\mathrm{p}} \approx 56 \mathrm{mV}\right.$, typical one-electron transfer kinetics $)<$ $\mathrm{Au}-\mathrm{MEODA}\left(\Delta E_{\mathrm{p}} \approx 90 \mathrm{mV}\right)<\mathrm{Au}-$ MEODA-MA $\left(\Delta E_{\mathrm{p}}>160 \mathrm{mV}\right)$. The increase in $\Delta E_{\mathrm{p}}$ with the accompanying decrease in voltammetric peak current densities clearly indicates that the modifiers provide a barrier to electron transfer of the redox species in solution. Impedance measurements performed at the equilibrium potential of the redox probe $\left(E_{1 / 2} \approx 0.27 \mathrm{~V}\right.$ vs. $\mathrm{Ag} \mid \mathrm{AgCl}$, saturated $\left.\mathrm{KCl}\right)$ showed that the size of the diameter of the semicircles (i.e., charge transfer resistance, $R_{\mathrm{ct}}$ value) increases as bare $\mathrm{Au}(0.0834 \mathrm{k} \Omega)<$ Au-MEODA (1.75 k $\Omega)<$ Au-MEODA-MA (14.5 k $\Omega$ ), indicating that electron transfer processes between the redox probe and the underlying gold surface are made more difficult with increasing layers of modifiers, corroborating the $\mathrm{CV}$ results. Au-MEODA-MA showed somewhat sigmoidal-shaped $\mathrm{CV}$ (typical of radial diffusion at microelectrodes), suggesting that electron transfer processes occur at the pinhole sites. ${ }^{9} \mathrm{~A}$ further EIS study is required to explore the integrity of these SAMs. EIS is less perturbing (smaller applied potential $\leq 10 \mathrm{mV}$ ) than $\mathrm{CV}$, which is particularly very crucial to soft materials as biomolecules, thus all further studies were carried out with EIS.

As represented in Scheme 2, the Au-MEODA-MA electrode was first modified by immersing in $1.5 \mathrm{mg} \mathrm{ml}^{-1}$ PBS-AE solution of saponin for 10 min to block non-specific binding sites. Human sera (obtained from a patient tested positive for both human immunodeficiency virus and tuberculosis $\left(\mathrm{HIV}^{+}-\mathrm{TB}^{+}\right)$and another patient tested negative for $\mathrm{HIV}$ and $\mathrm{TB}\left(\mathrm{HIV}^{-}-\mathrm{TB}^{-}\right)$as a control), originally collected for another study ${ }^{2}$ from the general medical wards

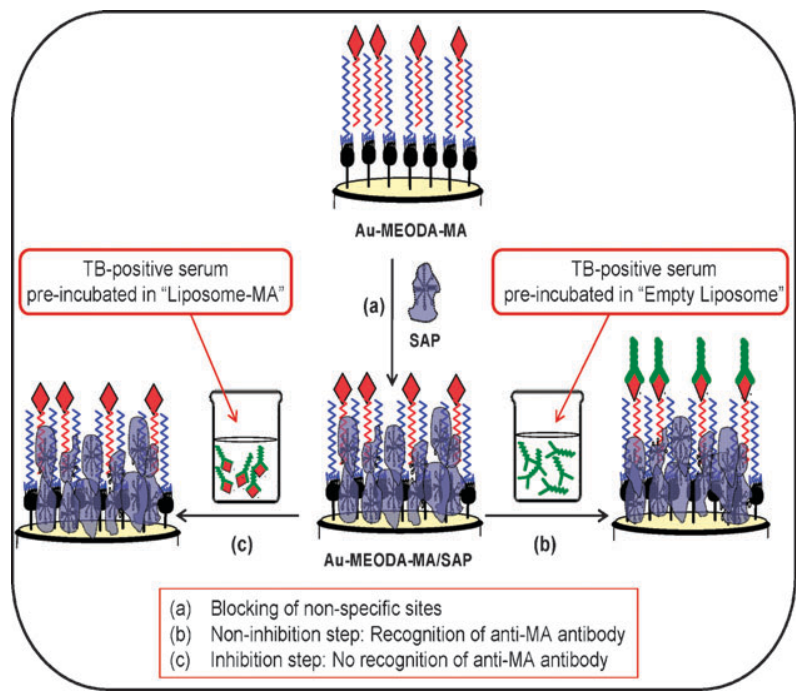

Scheme 2 Cartoon representation (not drawn to scale) of the modification of a $\mathrm{Au}-\mathrm{MEODA}-\mathrm{MA}$ electrode with a blocking agent (saponin, SAP) and subsequent interaction of the immobilized MA with anti-MA antibody in human TB-positive serum.

of the Helen Joseph Hospital, Johannesburg (South Africa), were used. The $\mathrm{HIV}^{+}-\mathrm{TB}^{+}$serum was obtained from a patient with newly-diagnosed smear-positive active pulmonary tuberculosis who was not on anti-TB chemotherapy at the time of serum collection. The $\mathrm{HIV}^{-}-\mathrm{TB}^{-}$patient was hospitalized for medical conditions other than TB or HIV, thereby constituting a better negative control than a healthy individual.

Physiological conditions (phosphate-buffered saline containing sodium azide $(0.025 \%, \mathrm{~m} / \mathrm{v})$ and $1 \mathrm{mM}$ EDTA (PBS-AE, $\mathrm{pH}$ 7.4)) were employed. Liposomes with MA ("liposome-MA") and without MA ("empty liposome") were prepared from a phosphatidylcholine (PC) $\mathrm{CHCl}_{3}$ stock solution $\left(100 \mathrm{mg} \mathrm{ml}^{-1}\right)$ (see ESI $\dagger$ ). Liposome mimics the natural environment of MA in the blood of TB patients.

Human sera $\left(\mathrm{HIV}^{+}-\mathrm{TB}^{+}\right.$and $\left.\mathrm{HIV}^{-}-\mathrm{TB}^{-}\right)$were appropriately diluted in empty liposome (PBS-AE pH 7.4) $(1: 2000 ; 1: 1000$ and $1: 500 \mathrm{v} / \mathrm{v}$, i.e., $0.05,0.1$ and $0.2 \%$ serum, respectively) and allowed to stand for $10 \mathrm{~min}$ at room temperature. For control experiments (using inhibited sera), a similar procedure was followed using liposomes containing MA (liposome-MA). The Au-MEODA-MA-SAP working electrode was incubated in the required serum solution for $10 \mathrm{~min}$ and was rinsed in a copious amount of PBS-AE (pH 7.4) to remove any loosely adsorbed species before performing the EIS experiments.

Fig. 1 exemplifies typical impedance spectral data obtained after immersing the electrodes in different concentrations of the human sera for $\mathrm{HIV}^{+}-\mathrm{TB}^{+}$patient (Fig. 1a), fitted with equivalent circuits involving Voigt circuits RC elements in series (see ESI $\dagger$, Fig. S2). The change in the total charge transfer resistance $\left(\Delta R_{\mathrm{ct}} / \Omega\right)$ for each concentration of the human sera was calculated from: ${ }^{10}$

$$
\Delta R_{\mathrm{ct}}=R_{\mathrm{Ag}-\mathrm{Ab}}-R_{\mathrm{Ag}}
$$

where $R_{\mathrm{Ag}}$ is the electrode polarization resistance of the $\mathrm{Au}-\mathrm{MEODA}-\mathrm{MA}-\mathrm{SAP}$ before incubation in the sera, while 

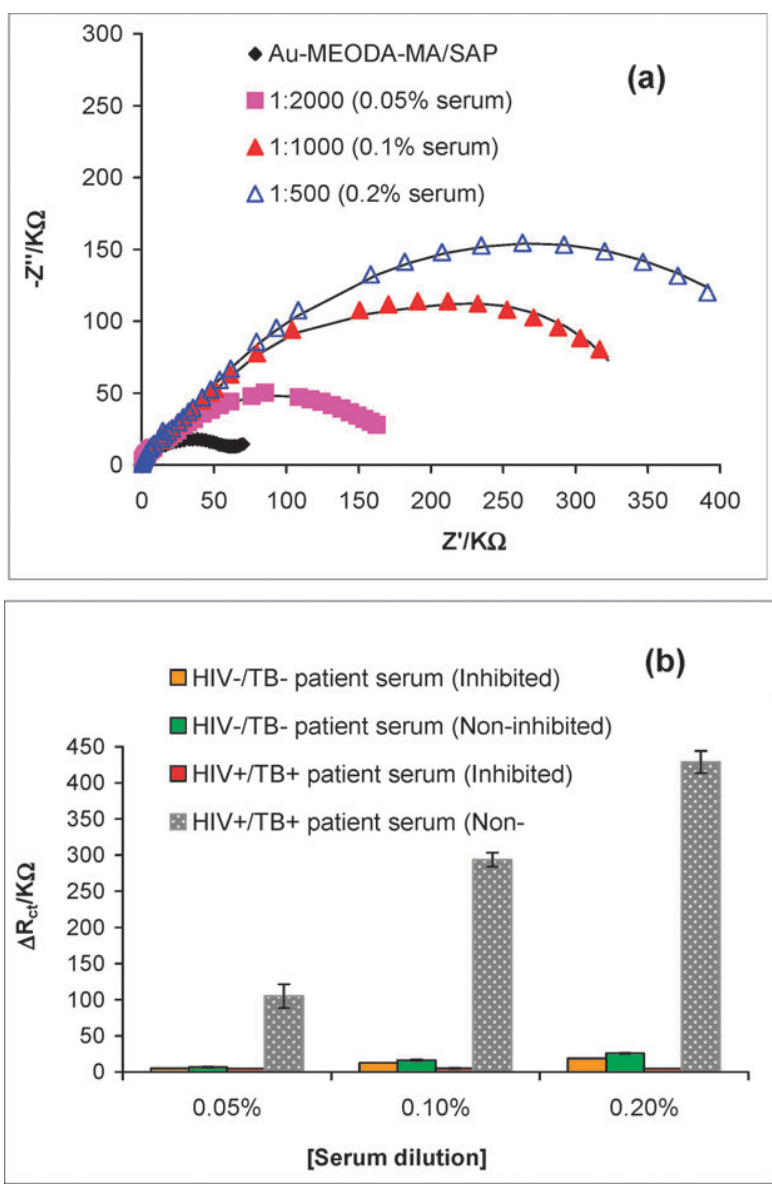

Fig. 1 (a) Typical serum concentration-dependent Nyquist plots of $\mathrm{Au}-$ MEODA-MA-SAP electrode incubated in $\mathrm{HIV}^{+} / \mathrm{TB}^{+}$patient serum. The respective incubating $\mathrm{HIV}^{+} / \mathrm{TB}^{+}$serum was diluted at $1: 500(0.20 \%$ serum $) ; 1: 1000(0.10 \%$ serum $)$ and $1: 2000(0.05 \%$ serum). Test solution: $1 \mathrm{mM}\left[\mathrm{Fe}(\mathrm{CN})_{6}\right]^{4-} /\left[\mathrm{Fe}(\mathrm{CN})_{6}\right]^{3-}(\mathrm{PBS}-\mathrm{AE}, \mathrm{pH}$ 7.4); potential bias $=0.27 \mathrm{~V}$ (vs. $\mathrm{Ag} \mid \mathrm{AgCl}$, saturated $\mathrm{KCl}$ ). The symbols represent the experimental data, while solid lines are fitted curves using equivalent circuits (see ESI $\dagger$, Fig. S2). (b) Comparative bar chart representation of the impedimetric detection signal obtained at the Au-MEODA-MA-SAP electrode for $\mathrm{HIV}^{+} / \mathrm{TB}^{+}$and $\mathrm{HIV}^{-} / \mathrm{TB}^{-}$patient sera.

$R_{\mathrm{Ag}-\mathrm{Ab}}$ is the value of the electrode polarization resistance after incubation of the Au-MEODA-MA-SAP in the serum solution.

The comparative results are represented as a bar chart (Fig. 1b). The impedance spectra for the $\mathrm{HIV}^{-}-\mathrm{TB}^{-}$patient serum (Fig. S3, ESI $\dagger$ ) and its control experiments (not shown) showed diffusion of the redox probe demonstrated by the straight line at low frequencies $\left(Z_{\mathrm{w}}\right)$. The $\mathrm{HIV}^{+}-\mathrm{TB}^{+}$patient sera showed complete blockage of diffusion, indicating the binding of the anti-MA antibodies in the sera and the interaction of these antibodies with the immobilized MA. Remarkably, the change in electrode polarization resistances in $\mathrm{HIV}^{+}-\mathrm{TB}^{+}$sera is approximately 10 times larger than that observed in the sera of the $\mathrm{HIV}^{-}-\mathrm{TB}^{-}$patient (see also Fig. S4, ESI $\dagger$ ), proving that the electrode could satisfactorily discriminate between positive and negative TB sera. The slight response observed with the $\mathrm{HIV}^{-}-\mathrm{TB}^{-}$patient sera may be ascribed to cross-reactivity, possibly with cholesterol, since MA may assume cholesteroid nature, ${ }^{11}$ suggesting that such slight interference may also be possible in the $\mathrm{HIV}^{+}-\mathrm{TB}^{+}$ patient sera analysis.

In conclusion, these results confirm for the first time the ability of an impedimetric immunosensor to discriminate between a positive and a negative TB patient serum. It is noteworthy that a dilution of $1: 20$ is the highest dilution where a significant binding to the antigens on the ELISA plates could be observed with most sera in ELISA by our groups. ELISA experiments were conducted with these two sera at the $1: 20$ dilution with a signal response ratio of $\mathrm{HIV}^{+}-\mathrm{TB}^{+}$to $\mathrm{HIV}^{-}-\mathrm{TB}^{-}$being $2: 1$. It is interesting to observe that this impedimetric immunosensor could detect very low dilution $(1: 2000)$ of antibodies in $\mathrm{HIV}^{+}-\mathrm{TB}^{+}$sera, which suggests that this could probably be a very sensitive immunosensor for active TB. Future studies should explore such factors as the impact of different redox probes; impedimetric assessment of the structural integrity of the SAM films; cross-reactivity with cholesterol; different TB sera; and applicability of cost-effective and easy-to-use one-shot electrodes for monitoring progress in TB treatment, especially the drug-resistant TB. All these will constitute the main thrust of future investigations in our laboratories.

We thank NRF (GUN \# 2073666, 65305, 68338, 45489), EDCTP (CT.2004.32040.001) and Cape Biotech/Lifelab for their support. NSM thanks NRF for bursary. We thank Ms Sandra van Wyngaardt for extracting the mycolic acids.

\section{Notes and references}

1 R. Uma Devi, B. Ramalingam and A. Raja, Diagn. Microbiol. Infect. Dis., 2003, 46, 205.

2 G. K. Schleicher, C. Feldman, Y. Vermaak and J. A. Verschoor, Clin. Chem. Lab. Med., 2002, 40, 882.

3 Md. Abdul Aziz, S. Park, S. Jon and H. Yang, Chem. Commun., $2007,2610$.

4 M. Díaz-González, M. B. González-García and A. Costa-García, Biosens. Bioelectron., 2005, 20, 2035.

5 N. Prabhakar, H. Singh and B. D. Malhotra, Electrochem. Commun., 2008, 10, 821.

6 C.-Z. Li, Y.-T. Long, J. S. Lee and H.-B. Kraatz, Chem. Commun., 2004, 574-575.

7 B. O. Agboola and K. I. Ozoemena, Phys. Chem. Chem. Phys., 2008, 10, 2399.

8 T. Hasegawa, J. Nishijo, M. Watanabe, K. Funayama and T. Imae, Langmuir, 2000, 16, 7325.

9 C. Amatore, J. M. Saveant and D. Tessier, J. Electroanal. Chem. Interfacial Electrochem., 1983, 147, 39.

10 R. Maalouf, C. Fournier-Wirth, J. Coste, H. Chebib, Y. Saïkali, O. Vittori, A. Errachid, J.-P. Cloarec, C. Martelet and N. JaffrezicRenault, Anal. Chem., 2007, 79, 4879.

11 Y. Benadie, M. Deysel, D. G. R. Siko, V. V. Roberts, S. Van Wyngaardt, S. T. Thanyani, G. Sekanka, A. M. C. Ten Bokum, L. A. Collett, J. Grooten, M. S. Baird and J. A. Verschoor, Chem. Phys. Lipids, 2008, 152, 95. 